\title{
PRESENCIA DE SAAVEDRA FAJARDO EN UN LIBRO DE EMBLEMAS NEERLANDÉS
}

THE PRESENCE OF SAAVEDRA FAJARDO IN A BOOK OF DUTCH EMBLEMS

Silvia Cazalla Canto

Universidad de Navarra

ABSTRACT • In 1668, the emblem book Het voorhof der ziele [The Antechamber of the Soul] was published in Rotterdam by the bookseller and humanist François van Hoogstraten. Its main argument conveys the concept of vanitas, since its point of departure is found in the Tratado de La Vanidad del mundo (Treatise of the Vanity of the World) by the Spanish preacher, friar Diego de Estella (1574). This work, rather than slavishly following the sources and content of the Spanish treatise, includes a series of variants that allow for the corroboration that it is neither plagiarism nor a translation of the Spanish original. These variant include the incorporation of works subsequent to the publication of Estella's work. o this end, the introduction of numerous quotations of the emblematist Diego Saavedra Fajardo is significant. The aim of this work is to carry out an analysis of the presence of the diplomat from Murcia in the Dutch text to determine the reasons that led Hoogstraten to introduce in his repertoire the most important Spanish emblematist of the Modern Age.

KEYWORDS: Emblematics; Modern Age; François van Hoogstraten; Diego de Estella; Diego Saavedra Fajardo; Vanity.

RESUMEN: • En 1668 vio la luz en Róterdam Het voorhof der ziele [Antesala del Alma], un libro de emblemas publicado por el librero y humanista François van Hoogstraten, cuyo argumento principal transmite el concepto de vanitas, ya que su punto de partida se sitúa en el Tratado de La Vanidad del mundo del predicador español fray Diego de Estella (1574). La obra, más allá de seguir casi al pie de la letra las fuentes y contenidos recogidos en el tratado español, posee una serie de variantes que permiten corroborar que no se trata ni de un plagio ni de una traducción del mismo, tales como la incorporación de obras posteriores a su publicación. En este sentido, resulta significativa la introducción de numerosas citas del emblemista Diego Saavedra Fajardo. El propósito de este trabajo es realizar un análisis de la presencia del diplomático murciano en el texto neerlandés para determinar los motivos que llevaron a Hoogstraten a introducir en su repertorio al emblemista español más importante de la Edad Moderna.

PALABRAS CLAVES: Emblemática; Edad Moderna; François van Hoogstraten; Diego de Estella; Diego Saavedra Fajardo; vanitas. 


\section{VANIDAD DEL MUNDO EN UN LIBRO DE EMBLEMAS NEERLANDÉS: EL FRUTO DE UN TRATADO RELIGIOSO ESPAÑOL}

En 1668, el librero y humanista de los Países Bajos, François van Hoogstraten, entregó a las prensas de Róterdam una obra perteneciente a la literatura emblemática que, destinada a un público general, mostraba la doctrina de vanitas: Het voorhof der ziele [Antesala del alma]. ${ }^{1}$ Configurada por sesenta emblemas que adoptan la composición tripartita propia de este género, transmite en cada una de sus declaraciones la idea de la fugacidad de la vida, la amenaza constante de la muerte y la necesidad de desprenderse de los bienes materiales del mundo para practicar la penitencia, la austeridad y la oración. De esta manera, aunque las picturae estén protagonizadas por escenas de muy variada naturaleza, gracias a las declaraciones se mantiene unitario el sentido que se quiere transmitir (Cazalla, 2017b).

Pero la clave de esta obra no reside ni en su forma ni en su contenido, sino en su origen: La Vanidad del mundo de fray Diego de Estella (1574); un tratado religioso del siglo XVI que, compuesto por tres partes de 100 capítulos cada una, versa en torno al concepto de vanitas, y es la fuente principal de la que bebe Antesala. Todo ello responde al hecho de que Hoogstraten tradujo durante casi una década la obra hispana en territorio neerlandés (1659-1665) y en consecuencia, en 1668 estaba plenamente capacitado para realizar una obra original con su punto de partida en La Vanidad (Cazalla, 2017a).

No obstante, a pesar de que la obra neerlandesa siga casi al pie de la letra a la hispana, existen indicios suficientes para constatar que no es un plagio de la misma, sobre todo si atendemos a su naturaleza (es un libro de emblemas), a su estructura (contiene 60 emblemas), a la transformación de la prosa en verso, y a las fuentes originales, algunas posteriores al texto español, entre las que destaca el emblemista Diego Saavedra Fajardo.

Con respecto a este último, la obra que llamó la atención de Hoogstraten fue su Idea de un príncipe político cristiano (Múnich, 1640; Milán, 1642) (Saavedra, 1999: 88-108). Su fortuna editorial fue descomunal a partir de la segunda mitad del siglo XVII al ser traducida a diversas lenguas del continente europeo, como el latín, francés, italiano, alemán, inglés y neerlandés. ${ }^{2}$ Por ello, no es de extrañar que Hoogstraten aprovechara su dominio del latín y manejara una de las seis ediciones compuestas entre 1649 y 1660, publicadas principalmente en Ámsterdam (Díez de Revenga, 1988: 57).

La presencia del emblemista español queda plasmada tanto en los motes como en los discursos de Antesala a la hora de incidir en la enseñanza moral que transmite. De esta manera son 11 las empresas que se presentan a lo largo del discurso de Hoogstraten con un total de 13 alusiones a Saavedra, ya que dos de ellas se repiten.

Pero, ¿por qué el autor neerlandés decidió enriquecer sus emblemas destinados a un público universal con una obra dedicada al príncipe? A priori podríamos determinar que la fama universal que adquirió Saavedra pudo ser una de las claves que consideró para dotar a su obra de las mismas características; no obstante, un profundo análisis de los argumentos que trata al mencionarlo, resulta indispensable para comprobar que va más allá de la simple selección de una obra célebre.

1. Este estudio se inscribe dentro del proyecto «Teatro, Literatura y Cultura Visual», del Grupo de investigación TRIVIUN de la Universidad de Navarra. Y a su vez se enmarca en el proyecto «Teatro, fiesta y cultura visual en la monarquía hispánica (ss. XVI-XVIII). Fase II», del Ministerio de Economía y Competitividad (MINECO), Subdirección General de Proyectos de Investigación (FFI2017-86801-P).

2. <http://www.studiolum.com/es/cd0l-saavedra.htm>19/01/2018 
A continuación realizaremos un análisis de aquellos emblemas, agrupados por temática, que acuden a las Empresas para intercalarlas en su discurso, para comprender el objetivo que persigue el libro de emblemas neerlandés con la presencia de Saavedra.

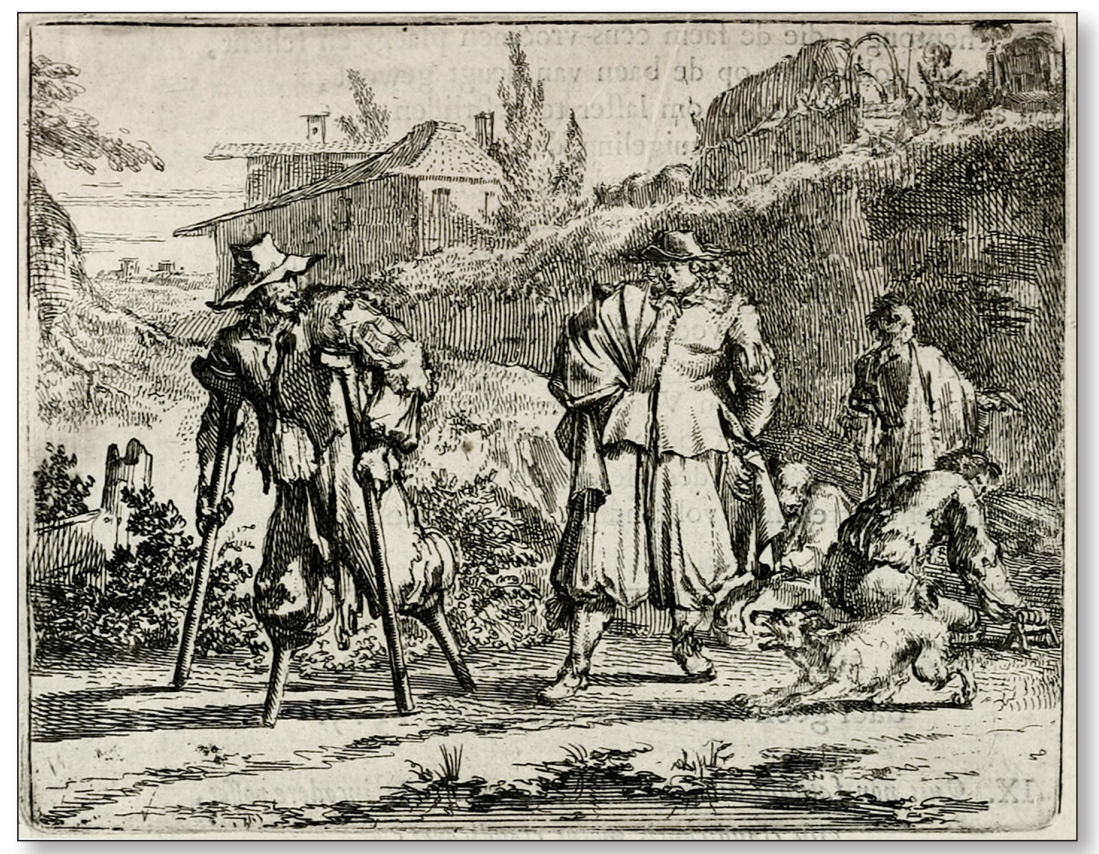

Fig. 1. François van Hoogstraten, Antesala del alma. Embl. 9.

\section{FACILLIME CORRIGUNTUR IN DISCENDO, QUORUM VITA IMITANTUR EMENDANDI CAUSA MAGISTRI [EL QUE HICIERE Y ENSEÑARE, ESTE SERÁ GRANDE EN EL REINO DE LOS CIELOS] ${ }^{3}$}

La moral es uno de los argumentos principales de la emblemática desde su nacimiento; con ella, los emblemistas se afanaron en exhibir una serie de testimonios que sirvieran para obtener una enseñanza ética. Fiel a este principio, Hoogstraten creará una serie de emblemas como pauta de comportamiento para una conducta honesta.

Así se refleja en el emblema 9, "Zy hebben gebeeft van vreeze, daer geen vreeze en was" [Ellos han temblado de miedo aunque no hubiera motivo] ${ }^{4}$ [fig. 1], cuya fuente se encuentra en el capítulo 11 de fray Diego, «De la vanidad de los que dejan el bien por lo que dice el mundo». En ambos se pone de relieve el error que cometen muchos al abandonar sus virtudes por temor al desprecio: «vanos son los que dejan el bien por la vergüenza del mundo», sentencia

3. Para los sucesivos subtítulos de este trabajo nos servimos de dos sentencias correlativas de Hoogstraten y Este-

lla que evidencian la interrelación que se establece entre ambos.

4. Sal 13,5.

IMAGO, NÚM. 10, 2018, 199-216 
Estella (1980: 26); "que abandonéis el camino de la virtud porque el mundo con sus elogios no te bendice [...] es apropiado de niños en la calle», dictamina Hoogstraten (1668: 20).

En la pictura observamos a un hombre con muletas mientras un joven renquea con afán burlesco, idea tomada de La Vanidad: "¿y quién no tendría por loco al que, movido por esta risa, anduviese cojeando pudiendo andar bien?» (Estella, 1980: 28). Esta mofa responde al objetivo de agradar al prójimo; un error de los que temen ser despreciados sin pensar en la estima divina, que es la verdaderamente importante: «los que temen la vergüenza presente y no la advenidera, temen la sombra y no la verdad», declara Estella (1980: 26-27).

Ambos recurren a distintos ejemplos para esclarecer el mensaje que desean transmitir: ${ }^{5}$

\begin{tabular}{|c|c|}
\hline Diego de Estella (1980: 28) & François van Hoogstraten $(1668: 21)$ \\
\hline $\begin{array}{l}\text { "Más temen los dichos de los hombres que } \\
\text { los hechos de Dios. Su locura se muestra en } \\
\text { dejarse vencer de los detraedores pudiéndolos } \\
\text { vencer» }\end{array}$ & $\begin{array}{l}\text { «de forma leve; pues no se precisa ninguna otra } \\
\text { fuerza que callar los pensamientos privados, y el } \\
\text { burlador con mejillas coloradas se irá». }\end{array}$ \\
\hline
\end{tabular}

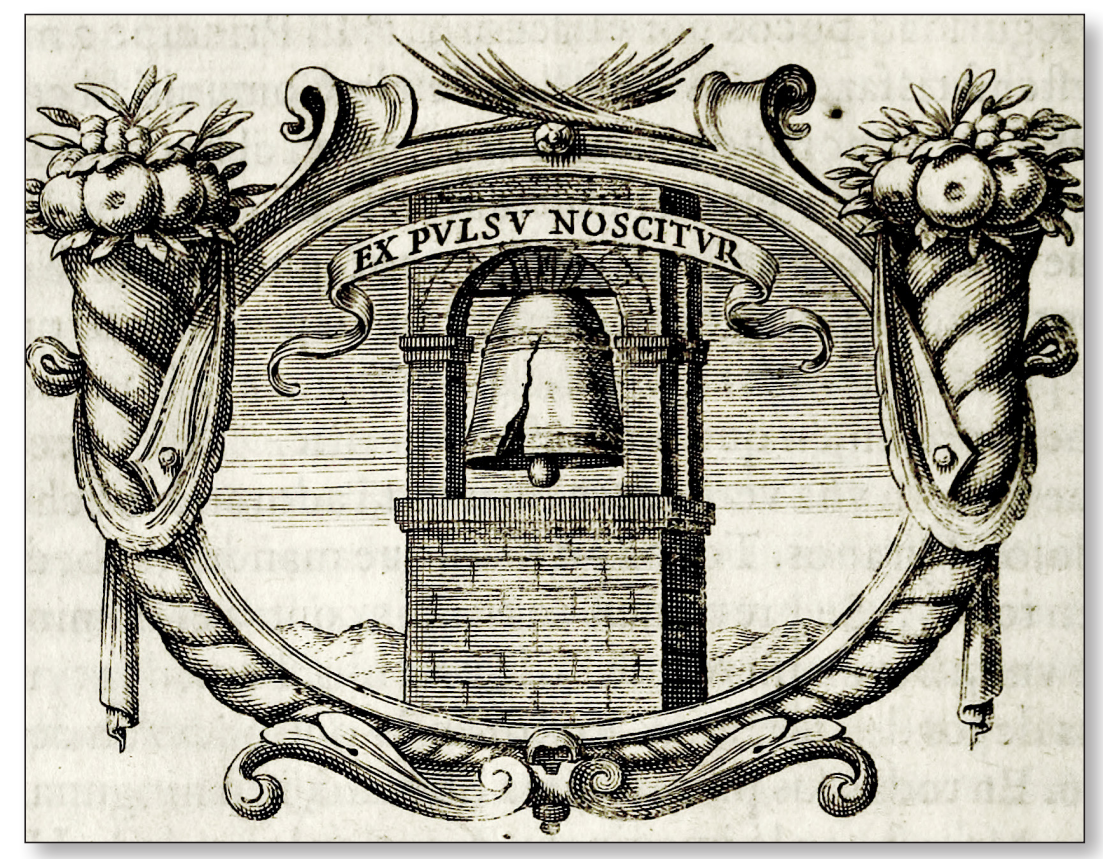

Fig. 2. Diego Saavedra Fajardo, Idea de un príncipe político cristiano. Emp. 11.

Son constantes las llamadas de atención sobre silenciar las palabras que dañan a unos y agradan a otros; momento en el que Hoogstraten recurre a Saavedra con una cita tomada de la empresa 11 [fig. 2], "Ex pulsu noscitur» [Se la reconoce al hacerla sonar], cuyo argumento principal gira en torno a la prudencia y a la meditación que debe realizar el príncipe antes

5. Is 30,15 . 
de emitir un juicio: «mucho se allega a su divinidad quien sabe callar» (Saavedra, 1659: 87; 1999: 282; Hoogstraten, 1668: 21). Las palabras y el silencio resultan ser el eslabón entre nuestros tres protagonistas.

Los tres autores consideran que nadie debería ser burlado o juzgado sólo por contento de otros y se pronuncian con el mismo pensamiento al concluir:

\begin{tabular}{|c|c|c|}
\hline $\begin{array}{c}\text { Diego de Estella } \\
(1980: 28)\end{array}$ & $\begin{array}{c}\text { François van Hoogstraten } \\
(1668: 21)\end{array}$ & \multicolumn{1}{|c|}{$\begin{array}{c}\text { Diego Saavedra } \\
(1999: 281)\end{array}$} \\
\hline $\begin{array}{l}\text { "Contra el fuego has de pelear } \\
\text { con agua, que es su contrario; } \\
\text { contra el parlero, con silencio» }\end{array}$ & $\begin{array}{l}\text { "él tiene sólo una boca, tú pue- } \\
\text { des con dos oídos soportarlo y } \\
\text { escuchar más que todos sus in- } \\
\text { sultos» }\end{array}$ & $\begin{array}{l}\text { "como ponemos freno al caba- } \\
\text { llo para que no nos precipite, le } \\
\text { debemos poner freno a la len- } \\
\text { gua». }\end{array}$ \\
\hline
\end{tabular}

Continúa el trío dando pautas de comportamiento a través de un discurso que mantiene el hilo del anterior. Hoogstraten lo hace en su emblema 12; Saavedra en la empresa 7; y Estella en el capítulo 14 (Cazalla, 2017c).

Personas que se mofan y emiten juicios de valores sobre sus prójimos con una actuación funesta, dan paso al emblema 23, "Saepius vindicta, quam dissimulatione deperditus fuit honos" [Más honras se han perdido en la venganza que en la disimulación] (Saavedra, 1659: 254; 1999: 449), que versa sobre la venganza de los humillados sobre sus burladores. Su declaración determina que si un profesor instruye a sus alumnos de manera errónea, estos adquirirán enseñanzas equívocas: «me pareció necesario usar este método de ir con baldes no a un arroyo espacioso ni donde están las fuentes, como se acostumbra por agua, sino allí donde el fuego chisporrotea" (Hoogstraten, 1668: 65). Es decir, es una metáfora sobre sostener un concepto o acto errado. Pero ¿cuál es la lección errónea que nos quiere revelar?

El emblema tiene su correspondencia con los capítulos 33 y 34 del estellés: «De la vanidad de los que vengan sus injurias" y "Cómo hemos de perdonar las injurias», aleccionadores sobre la necesidad de abandonar cualquier deseo de venganza; una actitud impropia del cristiano. Asevera Estella (1980: 86): «si dejares la venganza para Dios, él te vengará cumplidamente»; por lo tanto, una conducta que se nutra de este pecado no está sino condenada al menosprecio divino. Se muestra igualmente severo Hoogstraten (1668: 66): «quienes enfurecidos buscan estúpidos la humedad de placer en el incendio de venganza, entran en su camino de perdición». Solo en Dios está juzgar y vengar: ${ }^{6}$

La venganza será el nexo de unión entre estos dos autores con Saavedra. En su empresa 32, "Ne te quaesiveris extra» [No te busques fuera], alenta al príncipe a mantenerse firme ante acusaciones falsas, ya que «quien corre ligeramente a la venganza, más se deja llevar de la pasión que del honor» (Saavedra, 1999: 449). Tanto los autores hispanos como el neerlandés aseguran que la venganza descubre la maldad del alma y deja en evidencia al que fue insultado inicialmente. Ante ello, se muestran displicentes:

\begin{tabular}{|c|c|c|}
\hline $\begin{array}{c}\text { Diego Saavedra } \\
(1999: 449)\end{array}$ & $\begin{array}{c}\text { François van Hoogstraten } \\
(1668: 68)\end{array}$ & \multicolumn{1}{c|}{$\begin{array}{c}\text { Diego de Estella } \\
(1980: 88)\end{array}$} \\
\hline $\begin{array}{l}\text { "Queda satisfecha la ira, pero } \\
\text { más descubierta y pública la in- } \\
\text { famia" }\end{array}$ & $\begin{array}{l}\text { «tal deseo de venganza separa } \\
\text { de Dios, quiebra la paz entabla- } \\
\text { da entre Dios y el alma» }\end{array}$ & $\begin{array}{l}\text { "Si te vengaras de tu prójimo, } \\
\text { Dios se vengará de ti; y como } \\
\text { tratares a quien te ofendió, así } \\
\text { serás tratado por Dios». }\end{array}$ \\
\hline
\end{tabular}

6. Is 42,8 ; Lc 6,37 ; Jn 5,22-27.

IMAGO, NÚM. 10, 2018, 199-216 


\section{QUIS IGITUR ILLOS PUTET BEATOS, QUOS MISERI TRIBUUNT HONORES? [EL QUE AMA LA MALDAD, ABORRECE SU ÁNIMA]}

La capacidad moral de producir daño y disfrazarlo de bondad, da paso a dos emblemas de Hoogstraten que intercalan la misma empresa de Saavedra, ya que en ella se concentra la esencia del tema que quiere difundir en su combinación de imágenes y palabras.

Alcanzamos así el emblema 46, "Terstont als zy ge-eert zullen zijn ende verheven, zullen zy gelijk rook vergaen" [Tan pronto como hayan sido honrados y elevados, se disiparán como el humo], ${ }^{7}$ en el que se muestra a un hombre lanzando una piedra con una honda; idea proveniente del capítulo 74 de Estella, «De la vanidad de los que quieren sustentarse favoreciendo a los malos»: "como el que tira la piedra con la honda, así es el que honra al necio» (Estella, 1980: 193).

La piedra arrojada por una fuerza externa se convierte en un claro ejemplo de las personas que ascienden gracias al favor de otros, aunque no son conscientes de que «los que sin méritos suben con el favor de los hombres, en cesando este favor caen de su estado", garantiza Estella (1980: 193). Del mismo modo «las personas que para elevarse, se ayudan de procedimientos malignos [...] se hunden como una piedra abandonada del impulso de la honda», concluye Hoogstraten (1668: 145-146).

La relación entre Estella y Hoogstraten resulta evidente, y a ellos se suma Saavedra con su empresa 18, "A Deo» [De Dios], que promueve evitar una política basada en virtudes fingidas. Con ella, el neerlandés reitera su argumento: «es imposible que sepan mantener largo tiempo un extremo de maldades, no habiendo malicia tan advertida que baste a cautelarse sin quedar enredada en sus mismas artes" (Saavedra, 1659: 141; 1999: 339; Hoogstraten, 1668: 145). Es definitiva, la misma reflexión que veíamos en Estella y Hoogstraten tiene continuidad en Saavedra; un «lugar común» escogido para unificar un mismo concepto y conferirle cierto aroma a vanitas. De esta forma se complementan con sus afirmaciones:

\begin{tabular}{|l|l|l|}
\hline \multicolumn{1}{|c|}{$\begin{array}{c}\text { Diego Saavedra } \\
(1999: 341)\end{array}$} & \multicolumn{1}{|c|}{$\begin{array}{c}\text { François van Hoogstraten } \\
(1668: 144)\end{array}$} & \multicolumn{1}{c|}{$\begin{array}{c}\text { Diego de Estella } \\
\text { (1980: 192) }\end{array}$} \\
\hline $\begin{array}{l}\text { «la divina justicia, dejando a } \\
\text { uno con el reino se le quita vol- } \\
\text { viéndole de señor en esclavo» }\end{array}$ & $\begin{array}{l}\text { "quien solo se proponga alcan- } \\
\text { zar aquí la altura, tomará con el } \\
\text { favor del cielo, su último refu- } \\
\text { gio en el infierno» }\end{array}$ & $\begin{array}{l}\text { "pues cómo quieres que te sus- } \\
\text { tente Dios en tu estado tratando } \\
\text { mal a sus amigos?" }\end{array}$ \\
\hline
\end{tabular}

El siguiente emblema que reincide en el tema es el 52 [fig. 3], "Nos insensati vitam illorum aestimabamus infaniam $\theta$ finem illorum fine honore" [iInsensatos de nosotros! Su vida nos parecía una locura y su fin una ignominia] ${ }^{8}$. En esta ocasión la pictura muestra el momento en el que Cristo es presentado ante Herodes, quien se burla de Él vistiéndole con un espléndido manto. ${ }^{9}$

9. Lc 23,8-11. 


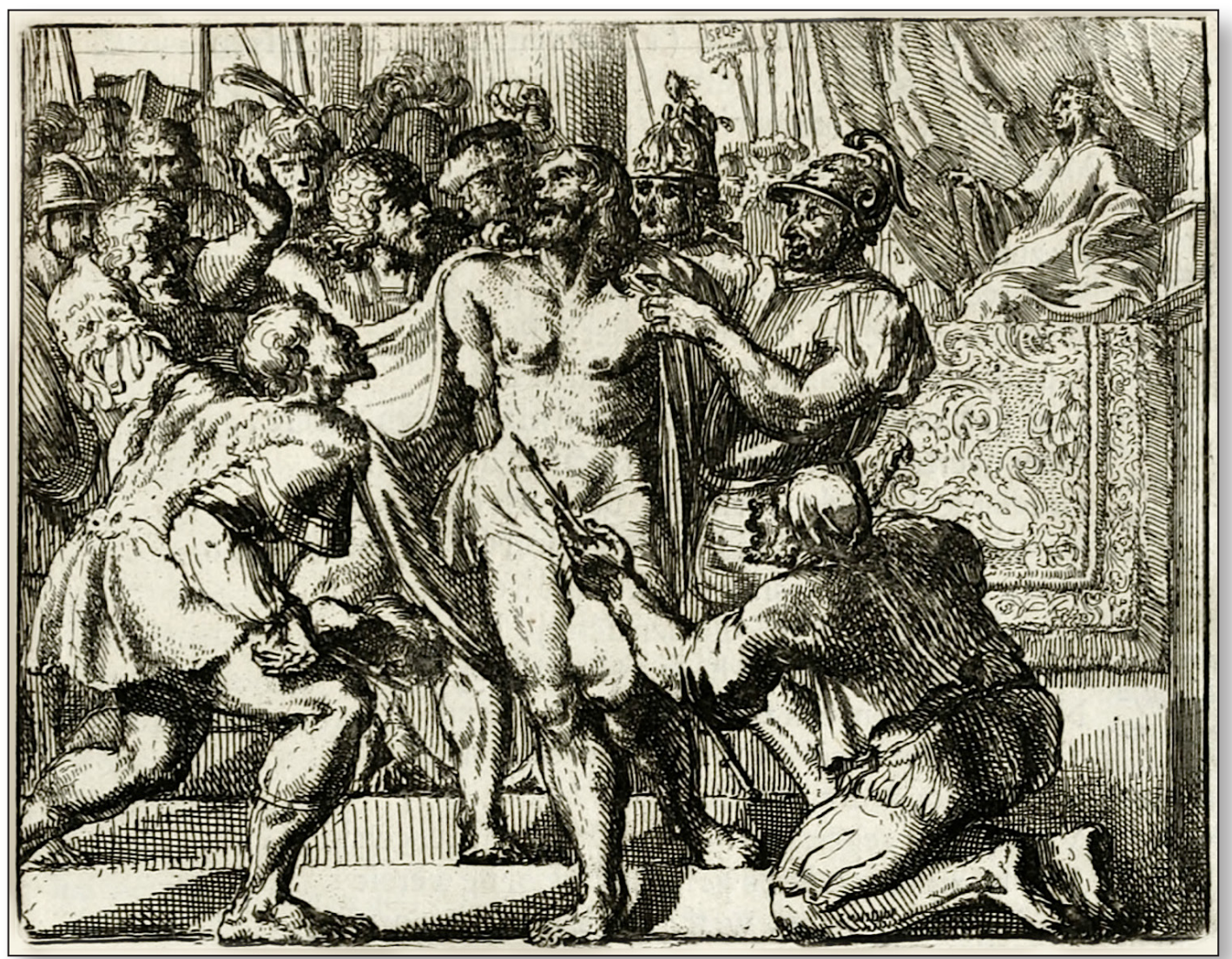

Fig. 3. François van Hoogstraten, Antesala del alma. Embl. 52.

Mote y grabado proceden del capítulo 85 de La Vanidad, "De la vana y loca sabiduría del mundo», en el que describe Estella (1980: 221): "el Redentor fue tenido por loco, y como si fuera tal lo trató el mundo, vistiéndole de ropa blanca en casa de Herodes». El episodio sirve a ambos autores como pretexto para extraer una enseñanza clara: la equívoca idea que tienen los hombres acerca de las personas que han alcanzado el poder con malicia. Estas últimas, normalmente saben disimular su astucia y pueden hacer pensar que son benévolos: "por sabio tiene el mundo al que disimulando sus vicios, sabe alcanzar dignidades y por locos a los que desprecian semejantes vanidades", afirma Estella (1980: 219); por su parte, exclama Hoogstraten (1668: 167-168): "a los hijos mundanos [...] los oprimen como si estuvieran locos mientras que honran al que con sus faltas, disimula con una bella apariencia».

Con esta afirmación alcanzamos de nuevo la empresa 18 de Saavedra a la que acude el neerlandés para acreditar su teoría: "cometer los vicios es fragilidad; disimular virtudes, malicia» (Saavedra, 1659: 137: 1999: 336: Hoogstraten, 1668: 168) [fig. 4]. Con ella significa que no es válida la política basada en virtudes fingidas, ya que no existe «ninguna maldad mayor que vestirse de la virtud para ejercitar mejor la malicia» (Saavedra, 1999: 336). 


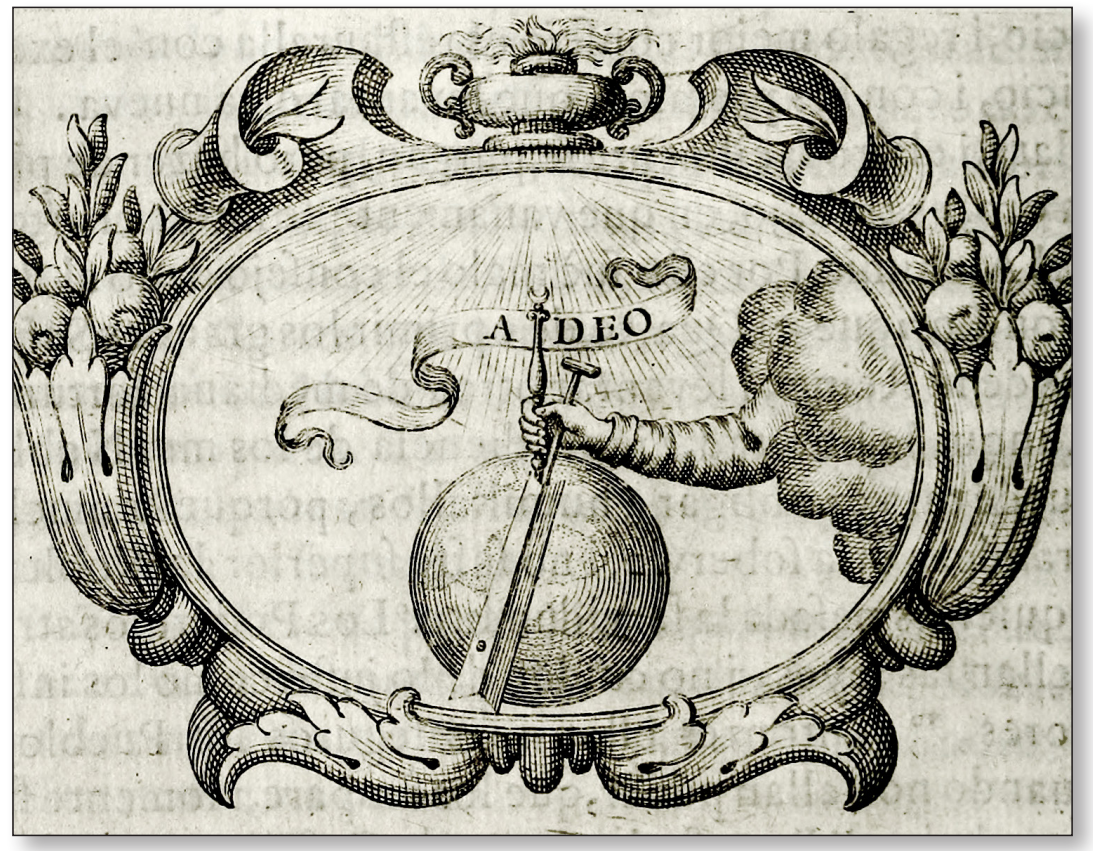

Fig. 4. Diego Saavedra Fajardo, Idea de un príncipe político cristiano. Emp. 18.

El alejamiento de Dios con respecto a esta actitud resulta evidente en los tres escritos; de este modo, las obras emblemáticas del siglo XVII dialogan con el texto del XVI:

\begin{tabular}{|l|l|l|}
\hline \multicolumn{1}{|c|}{$\begin{array}{c}\text { Diego Saavedra } \\
\text { (1999: 336) }\end{array}$} & \multicolumn{1}{|c|}{$\begin{array}{c}\text { François van Hoogstraten } \\
(1668: 168)\end{array}$} & \multicolumn{1}{|c|}{$\begin{array}{c}\text { Diego de Estella } \\
(1980: 220)\end{array}$} \\
\hline $\begin{array}{l}\text { «No reconoce de Dios la corona } \\
\text { y su conservación, ni cree que } \\
\text { premia y castiga el que fía más } \\
\text { de tales artes que de su divina } \\
\text { Providencia» }\end{array}$ & $\begin{array}{l}\text { "Quien está en el mundo alto } \\
\text { en honra es adorado por los hu- } \\
\text { mildes, pero indigno de aprecio } \\
\text { por Dios» }\end{array}$ & $\begin{array}{l}\text { "Loc buenos son tenidos en } \\
\text { poco de mundanos y son } \\
\text { muytimados de Dios». }\end{array}$ \\
\hline
\end{tabular}

Nuevamente renace la vanitas cuando concluyen nuestros tres autores:

\begin{tabular}{|l|l|l|}
\hline $\begin{array}{c}\text { Diego de Estella } \\
(1980: 220)\end{array}$ & $\begin{array}{c}\text { François van Hoogstraten } \\
(1668: 169)\end{array}$ & \multicolumn{1}{c|}{$\begin{array}{c}\text { Diego Saavedra } \\
(1999: 341)\end{array}$} \\
\hline $\begin{array}{l}\text { "La sabiduría terrena se mos- } \\
\text { trará ser locura, cuando aquel } \\
\text { que tanto trabajó en juntar ri- } \\
\text { quezas fuere metido bajo tie- } \\
\text { rra, desposeído de todo cuanto } \\
\text { tenía» }\end{array}$ & $\begin{array}{l}\text { es más allá. La difamación y el en } \\
\text { escarnio que nos molesta en la } \\
\text { vida, nos hace compañeros del }\end{array}$ & $\begin{array}{l}\text { "porque si bien vivió y murió } \\
\text { rey, fue desde entonces servi- } \\
\text { dumbre de su reinado». }\end{array}$ \\
\hline
\end{tabular}




\section{POPULAREM GRATIAM NE COMMEMORATIONE QUIDEN DIGNAM PUTO [SI A LOS HOMBRES CONTENTASE, NO SERÍA SIERVO DE CRISTO]}

El concepto de la fama que aspira al reconocimiento exterior cobró un protagonismo de primer orden en el marco del humanismo renacentista; sin embargo, la vanagloria y riquezas mundanas serán tratadas de diversa manera por Hoogstraten, quien siguiendo al predicador estellés, configurará una serie de emblemas alusivos a este concepto.

Iniciamos con el emblema 10, "Christi bonus odor sumus deo" [Somos buen olor de Cristo en todo lugar],$^{10}$ inspirado en el capítulo 12 del navarro, "De la vanidad de los que desprecian su propia fama». Observamos en él una meditación en torno a aquellas personas que desoyen las opiniones que otros poseen sobre ellas; un arduo error, puesto que la reputación debe ocupar un puesto de primer orden en el pensamiento.

Esta idea tiene un objetivo: enmendar nuestros errores. Es decir, tras conocer cuál es la fama precedente, se deben corregir los fallos cometidos para dar un buen ejemplo al resto: «haced el bien, no sólo delante de Dios, sino también delante de los hombres [...] Somos buen olor de Cristo en todo lugar» (Estella, 1980: 31). Y aquí tiene su punto de partida el emblema de Hoogstraten.

A raíz de la sentencia bíblica, el neerlandés no sólo configura el mote de su emblema, sino que el grabado exhibe un grupo de hombres pertenecientes a distintos estamentos, entre los cuales destaca un monje que sostiene un incensario para purificar las almas de todos los que desean obtener honor: «el perfume de mi incienso, capaz de repeler el vapor sucio de vuestra alma, allí donde el placer fue débil y os pudo dominar» (Hoogstraten, 1668: 23). Se suman a ella alusiones a otras historias bíblicas comparando personajes que obraron bien gracias a su buena fama ${ }^{11}$ con otros que erraron por su pérdida. ${ }^{12}$

En definitiva, ambos autores aconsejan conocer nuestra reputación para realizar un ejercicio de introspección y ser conscientes de las carencias que poseemos con la idea de subsanarlas y actuar honestamente, para dar buen ejemplo al prójimo.

Llegados a este punto, Hoogstraten inserta en su discurso la empresa 15 de Saavedra, «Dum luceam peream» [Estime más la fama que la vida]. En ella aconseja al príncipe a procurarse una buena opinión del pueblo con sus buenas acciones: "no hay vida tan corta que no tenga espacio para obrar generosamente» (Saavedra, 1999: 310). Alecciona sobre la necesidad de alcanzar buena fama a través de grandes hazañas; por ello, el neerlandés escoge meticulosamente la sentencia que unirá el argumento de Estella y el suyo con el de Saavedra (1659: 119; 1999: 313; Hoogstraten, 1668: 24): «despreciando la fama, desprecian las virtudes». De esta manera, muestran la necesidad de obtener buena fama para mantenerse en la virtud y odiar aquellos vicios que, disfrazados de gloria, son pura vanidad:

\begin{tabular}{|l|l|l|}
\hline \multicolumn{1}{|c|}{$\begin{array}{c}\text { Diego de Estella } \\
\text { (1980: 32) }\end{array}$} & \multicolumn{1}{|c|}{$\begin{array}{c}\text { François van Hoogstraten } \\
(1668: 24)\end{array}$} & \multicolumn{1}{c|}{$\begin{array}{c}\text { Diego Saavedra } \\
\text { (1999: 313) }\end{array}$} \\
\hline $\begin{array}{l}\text { «debes conservar la buena } \\
\text { fama, pues te refrena de pecar } \\
\text { y te incita a obrar bien" }\end{array}$ & $\begin{array}{l}\text { "el que aprecie su buena fama, } \\
\text { odiará los pecados sucios, quien } \\
\text { la descuide, abandonará tam- } \\
\text { bién las virtudes" }\end{array}$ & $\begin{array}{l}\text { ambición honesta teme } \\
\text { mancharse con lo vicioso [...] } \\
\text { Lo que parece glorioso deseo es } \\
\text { vanidad». }\end{array}$ \\
\hline
\end{tabular}

10. 2 Cor 2,15

11. Jdt 8,8 .

12. Jer 3,1

IMAGO, NÚM. 10, 2018, 199-216 
No obstante, la pretensión de Hoogstraten con este emblema no finaliza en una única mención a Saavedra. También se apropia de las ideas de su empresa 16, "Purpura iuxta purpuram» [La púrpura según la púrpura], en cuya declaración se manifiesta una teoría que se descubre también en Estella: el deber de comparar dos acciones similares.

En su instrucción al futuro rey, Saavedra le aconseja confrontar sus acciones con las de sus antepasados; así mejorará sus actos y alcanzará la fama de sus antecesores: «nunca mueven más los ejemplos que al lado de otros opuestos" (Saavedra, 1659: 123; 1999: 318; Hoogstraten, 1668: 23).

Por lo tanto, cotejar opiniones y acciones asegura, en el caso de Estella y Hoogstraten, continuar en el camino de la virtud y, en el de Saavedra, un buen gobierno:

\begin{tabular}{|l|c|c|}
\hline \multicolumn{1}{|c|}{$\begin{array}{c}\text { Diego de Estella } \\
\text { (1980: 30) }\end{array}$} & $\begin{array}{c}\text { François van Hoogstraten } \\
(1668: 24)\end{array}$ & $\begin{array}{c}\text { Diego Saavedra } \\
(1999: 321)\end{array}$ \\
\hline $\begin{array}{l}\text { «Bueno es tener cuenta lo que } \\
\text { se dice, porque si con verdad } \\
\text { murmura, te servirá de correc- } \\
\text { ción y si con mentira, te será } \\
\text { causa de mérito" }\end{array}$ & $\begin{array}{c}\text { "y poned para discernir entre la } \\
\text { verdad y mentira, los elogios }\end{array}$ & $\begin{array}{c}\text { "este cotejo será el más seguro } \\
\text { para el acierto de su gobierno". }\end{array}$ \\
\hline
\end{tabular}

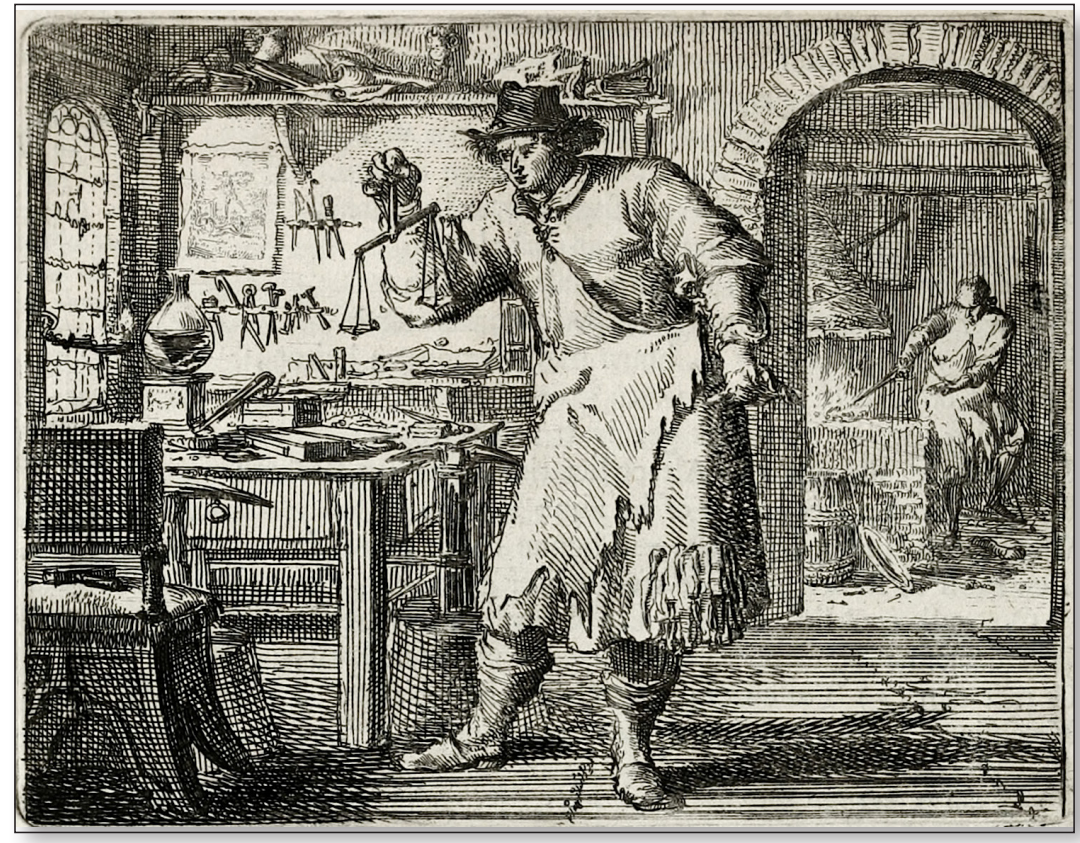

Fig. 5. François van Hoogstraten, Antesala del alma. Embl. 15.

El siguiente emblema de Hoogstraten relacionado con la fama es el 15 [fig. 5], «Major illius fama est et opinio, qui plus eam celare contendit» [La fama y opinión se concibe mayor de quien se oculta a ella], cuyo mote proviene de la empresa 10 de Saavedra, "Fama nocet" [La fama perjudica] (Saavedra, 1659: 79; 1999: 274; Hoogstraten, 1668: 37) [fig. 6], y se corresponde con los capítulos 18 a 20 de Estella: "De la vanagloria», "Del desprecio de la vanagloria» y «De la vanidad de los que se alaban a sí mismos». 


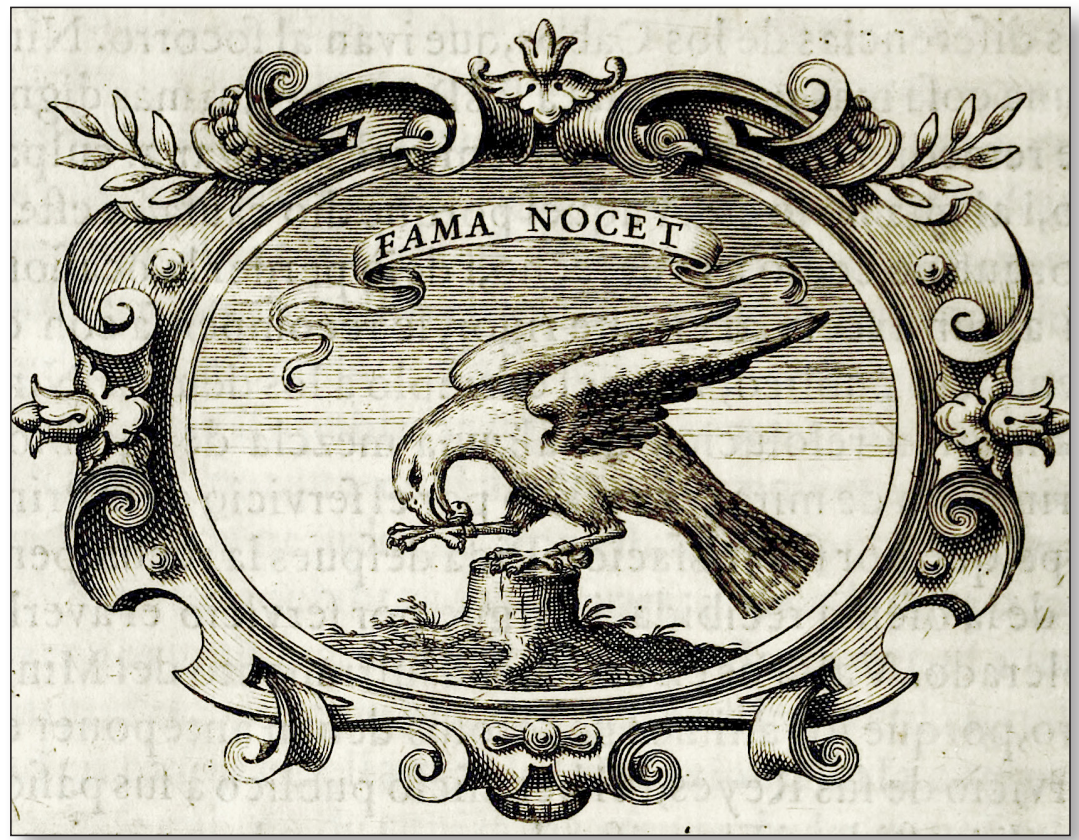

Fig. 6. Diego Saavedra Fajardo, Idea de un príncipe político cristiano. Emp. 10.

Si atendemos a la pictura, observamos cómo un orfebre en su taller sostiene una balanza descompensada aunque ambos platillos aparecen vacíos, alegoría proveniente de Estella (1980: 53): «la balanza cuanto está más vacía más sube arriba, así cuando el hombre es más inútil, más se alaba a sí mismo [...] cuanto la balanza es más pesada, más desciende, y así el hombre cuanto más virtuoso es se desprecia más a sí mismo». Por su parte, Hoogstraten confiesa que el engaño del orfebre al situar platillos desiguales en la balanza posee una intención moralizante: «mi cruz, equipada con platillos desiguales era su guía para [...] un alma que cayó bajo el desagradable vapor de su propia fama [...] un piadoso, no acostumbrado a alabarse, reconocía a su Dios como el origen verdadero de lo bueno" (Hoogstraten, 1668: 38). En definitiva, ambos autores reconocen en sus escritos una idea clara: el desprecio de la propia fama.

Sintoniza con la idea anterior la empresa 10 de Saavedra que ilustra al príncipe sobre el concepto de fama, aconsejándole mostrarse como semejante a sus prójimos: "como hay hipocresía que finge virtudes y disimula vicios, así conviene que al contrario la haya para disimular el valor y apagar la fama" (Saavedra, 1999: 271-272).

El desprecio por la fama se presenta aquí de manera concisa; sin embargo, resulta interesante constatar cómo si bien Estella y Hoogstraten sentencian a aquellos que se vanaglorian de sus acciones, cuando en realidad provienen de Dios, Saavedra elabora un símil entre los súbditos del rey y este: «los ministros advertidos deben atribuir los felices sucesos a su príncipe» (Saavedra, 1999: 274). En definitiva, los tres aconsejan menospreciar la reputación y mostrarse humildes antes los demás: 


\begin{tabular}{|l|c|c|}
\hline $\begin{array}{c}\text { Diego Saavedra } \\
(1999: 273-274)\end{array}$ & $\begin{array}{c}\text { François van Hoogstraten } \\
(1668: 39)\end{array}$ & \multicolumn{1}{c|}{$\begin{array}{c}\text { Diego de Estella } \\
(1980: 49)\end{array}$} \\
\hline $\begin{array}{l}\text { «es gran sabiduría ocultar } \\
\text { la fama [...] teniendo entre } \\
\text { cenizas los pensamientos altos" }\end{array}$ & $\begin{array}{l}\text { "pero el que presume de su } \\
\text { propio elogio [...] observe como } \\
\text { la virtud lo puede bajar» }\end{array}$ & $\begin{array}{l}\text { "pues cuando hurtas la gloria, } \\
\text { que es de Dios, quítate Dios el } \\
\text { provecho, que era tuyo» }\end{array}$ \\
\hline
\end{tabular}

La necesidad de abandonar la ambición para no ser víctimas de la vanagloria mundana y poder disfrutar de la gloria divina tras la llegada de la muerte, se exhibe en el emblema 18 de Hoogstraten, cuya correspondencia se sitúa en el capítulo 23 de fray Diego y donde incluye la empresa 9 de Saavedra (Cazalla, 2017c).

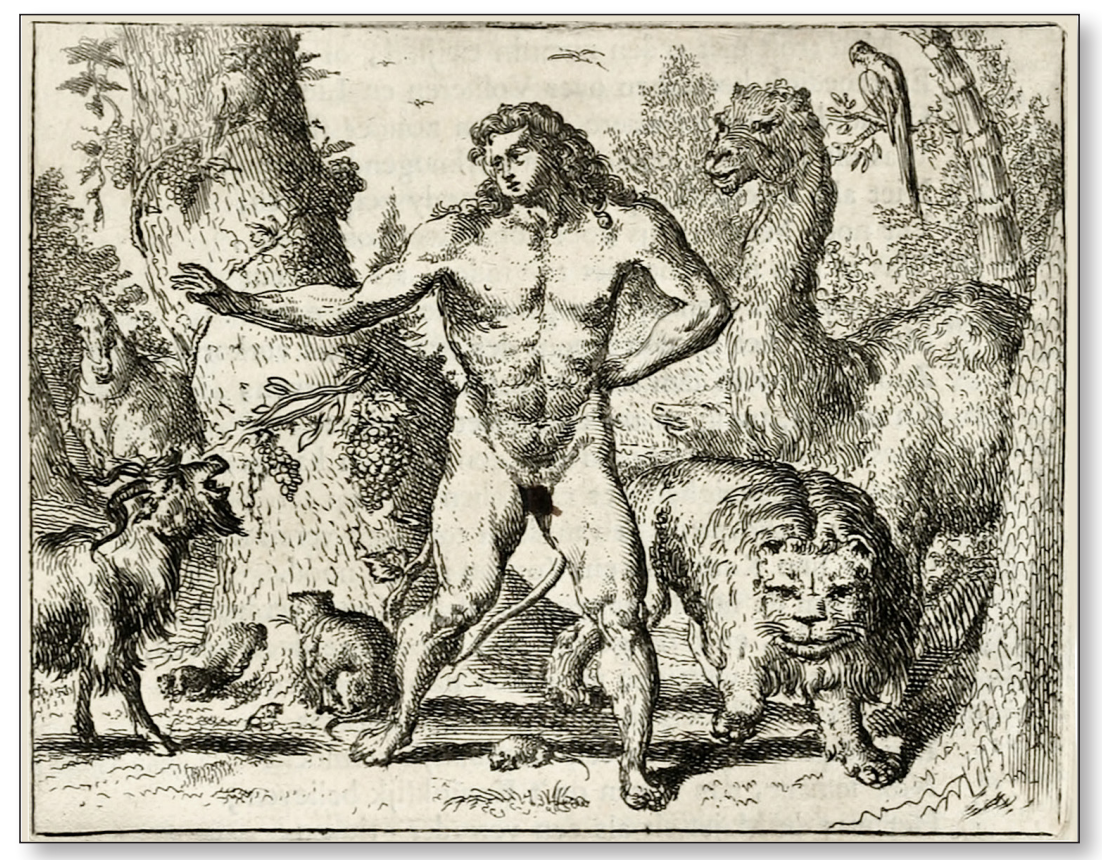

Fig. 7. François van Hoogstraten, Antesala del alma. Embl. 19.

El argumento de la fama continua en el emblema 19 [fig. 7] «Sicut dies mercenarij dies ejus» [Y como día de mercenario son sus días], que encuentra su analogía en el capítulo 24 de Estella: «De la vanidad del señorío mundano». En la pictura, Hoogstraten materializa las palabras de Estella al afirmar: «cuando Dios crió al hombre, no le fue dado señorío para mandar a otro hombre, sino solamente para que se enseñorease de las bestias de la tierra y de los peces y aves» ${ }^{13}$ (Estella, 1980: 51). Así, en el grabado se halla una escena bíblica en la que aparece Adán en el paraíso presidiendo los animales.

El desprecio de las riquezas terrenales trasciende más allá y se dirige también a los altos estamentos, cuyo poder ha sido otorgado por Dios: «así surgieron en el mundo, aunque

13. Gen 1,28-30. 
a Dios le doliera, los reinados y el poder [...] en nombre de Dios han sido otorgados y no ambicionados por personas», esclarece Hoogstraten (1668: 52); además, profundizan en una segunda idea: «aunque seas grande prelado, rey y emperador ¿qué hay después? ¿Te librarán estas cosas de la muerte?», demanda Estella (1980: 62). En definitiva, la fugacidad de la vida y de las cosas mundanas son las claras protagonistas.



Fig. 8. Diego Saavedra Fajardo, Idea de un príncipe político cristiano. Emp. 20.

Comulga con ellos la empresa 20 de Saavedra [fig. 8], «Fallax bonum» [Falso bien], donde alecciona al monarca a no codiciar más poder del que posee, ya que de lo contrario, su gobierno peligraría: «no hay en la corona perla que no sea sudor. No hay rubí que no sea sangre» (Saavedra, 1659: 150; 1999: 128; Hoogstraten, 1668: 53).

La codicia se presenta deplorable para los tres autores, pues todo en la tierra es humo:

\begin{tabular}{|l|l|l|}
\hline $\begin{array}{c}\text { Diego Saavedra } \\
(1999: \text { 354-355) }\end{array}$ & $\begin{array}{c}\text { François van Hoogstraten } \\
(1668: 53)\end{array}$ & \multicolumn{1}{c|}{$\begin{array}{c}\text { Diego de Estella } \\
(1980: 62)\end{array}$} \\
\hline $\begin{array}{l}\text { "Conténtese con mantener su } \\
\text { corona con la misma potestad } \\
\text { que sus antepasados. Esto pare- } \\
\text { ce que dio a entender Dios» }\end{array}$ & $\begin{array}{l}\text { "el mundo es el reino de Dios; } \\
\text { por eso de ninguna manera se- } \\
\text { ría apropiado que el hombre es- } \\
\text { calase alto y empinado» }\end{array}$ & $\begin{array}{l}\text { "todo se ha de quedar acá y } \\
\text { desposeído de cuanto tienes, } \\
\text { entrarás desnudo en una pobre } \\
\text { y angosta sepultura». }\end{array}$ \\
\hline
\end{tabular}




\section{AB OMNI PHILOSOPHIA VIDETUR ALIENUS, QUI MISERIUS DUCIT MORI NATUM, QUAM NASCI MORITURUM [SI VIVIMOS O MORIMOS, DEL SEÑOR SOMOS]}

Si bien en los anteriores apartados nuestros protagonistas establecen una enseñanza moral cercana a la vanitas, ahora el mensaje propuesto ahonda plenamente en ella y nos conduce sin atajos a la muerte.

El primero de ellos es el 29, "Qui genus jactat suum, aliena laudat» [El que hace vanidad de su nobleza, ensalza la gloria de otros], correspondiente a los capítulos 41 y 42 de Estella, "De la vanidad de la nobleza del linaje», "De la verdadera nobleza», dirigidos a un sector concreto de la sociedad: la nobleza y la monarquía.

Desde el inicio, arremete contra aquellos que, pertenecientes a este estrato social, se estiman como virtuosos, cuando la nobleza se adquiere por virtudes: «vanidad es muy grande [...] preciarse de la nobleza del linaje» (Estella, 1980: 106); «sé virtuoso y en ti comenzará la nobleza, aunque tus pasados no la hayan tenido. Si siendo noble eres apocado, en ti se acaba la nobleza de tu sangre» (Estella, 1980: 107). Con estas palabras se resume la idea que quiere difundir.

Este concepto se plasma en Hoogstraten, quien en su pictura introduce a un personaje que corta la espina de un rosal frente a otro que le observa: «de una raíz nace la espina y la rosa, y de una madre puede nacer el noble y el hijo vil. Bien puedes nacer de la raíz de donde proceden rosas y varones ilustres y ser tú una vil espina» (Estella, 1980: 107).

Se suma a esta concepción la empresa 17 de Saavedra, "Alienis spoliis» [Con trofeos ajenos], donde instruye al príncipe sobre la obligación de emular las proezas de sus antepasados para adquirir las virtudes que convirtieron su estirpe en nobleza; de lo contrario, no merecerá su gloria: «así las hazañas de los antepasados son confusión al sucesor que no las imita" (Saavedra, 1659: 125; 1999: 332; Hoogstraten, 1668: 85).

A partir de aquí, toda la concepción de ser virtuoso para obtener la hidalguía de los antepasados se sumerge en una atmósfera de vanitas, donde ser honrado es una de las herramientas necesarias para lograr la Gloria Divina:

\begin{tabular}{|c|c|c|}
\hline $\begin{array}{c}\text { Diego Saavedra } \\
\text { (1999: 328) }\end{array}$ & $\begin{array}{c}\text { François van Hoogstraten } \\
\text { (1668:87) }\end{array}$ & $\begin{array}{l}\text { Diego de Estella } \\
\text { (1980: 109) }\end{array}$ \\
\hline $\begin{array}{l}\text { «En queriendo los hombres ser } \\
\text { con la magnificencia más de lo } \\
\text { que pueden, vienen a ser menos } \\
\text { de lo que son y a extinguirse las } \\
\text { familias nobles» }\end{array}$ & $\begin{array}{l}\text { "ipensad oh, almas cristianas! } \\
\text { Los gusanos me roerán y } \\
\text { destruirán como ha sucedido } \\
\text { con mis antepasados: la nobleza } \\
\text { de ellos recibida es muerte». }\end{array}$ & $\begin{array}{l}\text { «no perdonarán a ti los gusanos } \\
\text { que comen en las sepulturas a } \\
\text { aquellos que te engendraron. } \\
\text { La nobleza que de ellos here- } \\
\text { daste fue mortalidad». }\end{array}$ \\
\hline
\end{tabular}

Tanto el siguiente emblema como el capítulo de Estella y la inserción de Saavedra, desempeñan un significativo papel de vanitas, por cuanto se desenvuelven en la idea de la muerte venidera que debe ser esperada con desasosiego, ya que es con ella cuando realmente comienza la verdadera vida.

El emblema 54 de Hoogstraten [fig. 9], «Ennius: nemo me lachrymis decoret, nec funera fletu faxit» [Ennio: que nadie me honre con lágrimas ni mis pompas con llanto célebre], ejemplifica la idea de resurrección, pues su pictura muestra un árbol revestido de nieve con el propósito de apaciguar el ánimo de las personas que lloran la pérdida de un ser querido: "cuando la muerte venga con su guadaña, y corte la vida de justos, puedes compararlos con 


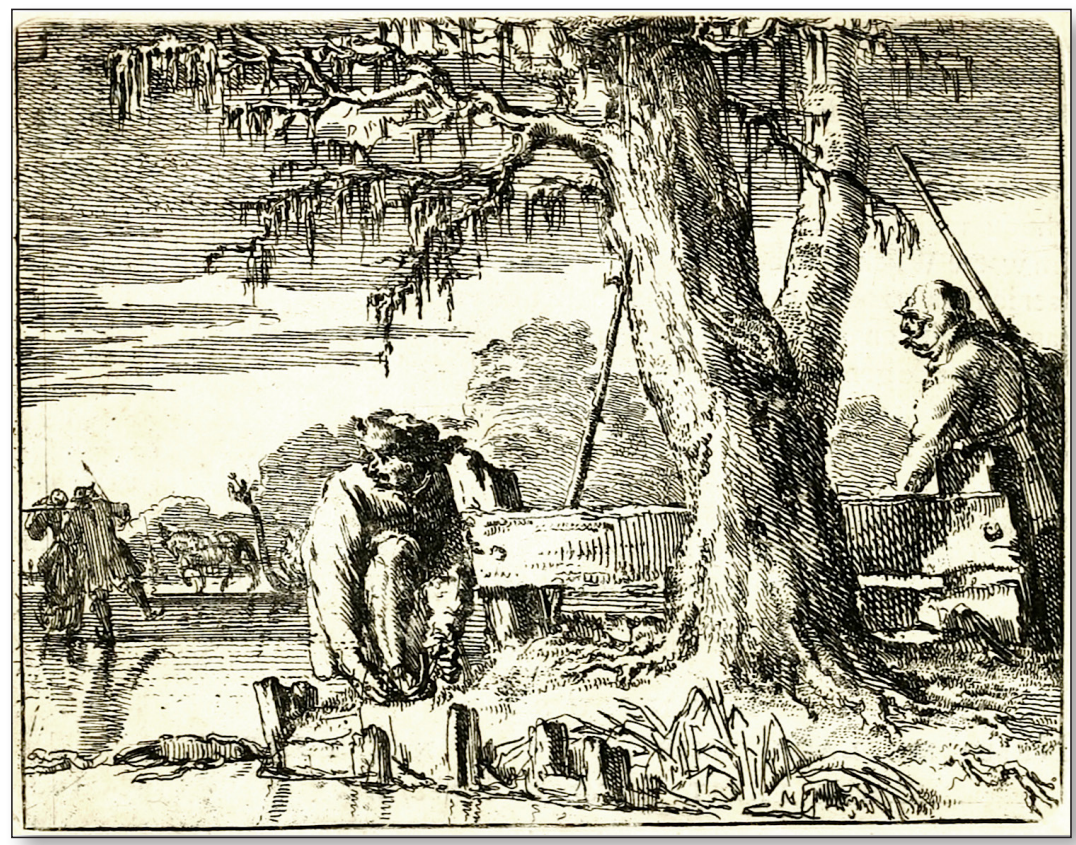

Fig. 9. François van Hoogstraten, Antesala del alma. Embl. 54

los árboles. Cuando ellos esconden la vida por un tiempo se levantarán el día del Juicio Final con brillo inmortal» (Hoogstraten, 1668: 175). La misma idea se atisba en Estella (1980: 227): "como el árbol en el invierno está marchito pero en verano se muestra hermoso; cuando viniere la resurrección aparecerán los justos cargados de fruta y muy gloriosos».

Coincide con ellos Saavedra, quien en su empresa 101 [fig. 10], "Futurum indicat» [Pronostica el futuro], trata el tema de la muerte con júbilo: «natural es el horror al sepulcro, pero si en nosotros fuese más valiente la razón que el apetito de vivir, nos regocijaríamos cuando llegásemos a la vista de él» (Saavedra, 1659: 821; 1999: 1038-1039; Hoogstraten, 1668: 176).

Los tres se muestran afables ante el óbito, en el que ven el inicio y no el final de la vida, un trance hacia un estado de paz. Por ello, alientan a sus lectores a anhelar la muerte en un diálogo a tres bandas en el que se magnifica el momento final:

\begin{tabular}{|l|l|l|}
\hline \multicolumn{1}{|c|}{$\begin{array}{c}\text { Diego de Estella } \\
(1980: 226)\end{array}$} & \multicolumn{1}{|c|}{$\begin{array}{c}\text { François van Hoogstraten } \\
(1668: 176)\end{array}$} & \multicolumn{1}{c|}{$\begin{array}{c}\text { Diego Saavedra } \\
\text { (1999: 1039) }\end{array}$} \\
\hline $\begin{array}{l}\text { «Terrible y temerosa era la muer- } \\
\text { te antes que Cristo muriese; pero } \\
\text { con su muerte no es para nosotros } \\
\text { muerte sino sueño" }\end{array}$ & $\begin{array}{l}\text { "entonces deténgase el duelo por- } \\
\text { que ningún fiel, si en Dios muere, } \\
\text { debe ser lamentado, sino que se le } \\
\text { desee mucha suerte en el viaje al } \\
\text { cielo» }\end{array}$ & $\begin{array}{l}\text { "porque en el sepulcro ha- } \\
\text { lla alma el verdadero te- } \\
\text { soro de la quietud eterna». }\end{array}$ \\
\hline
\end{tabular}




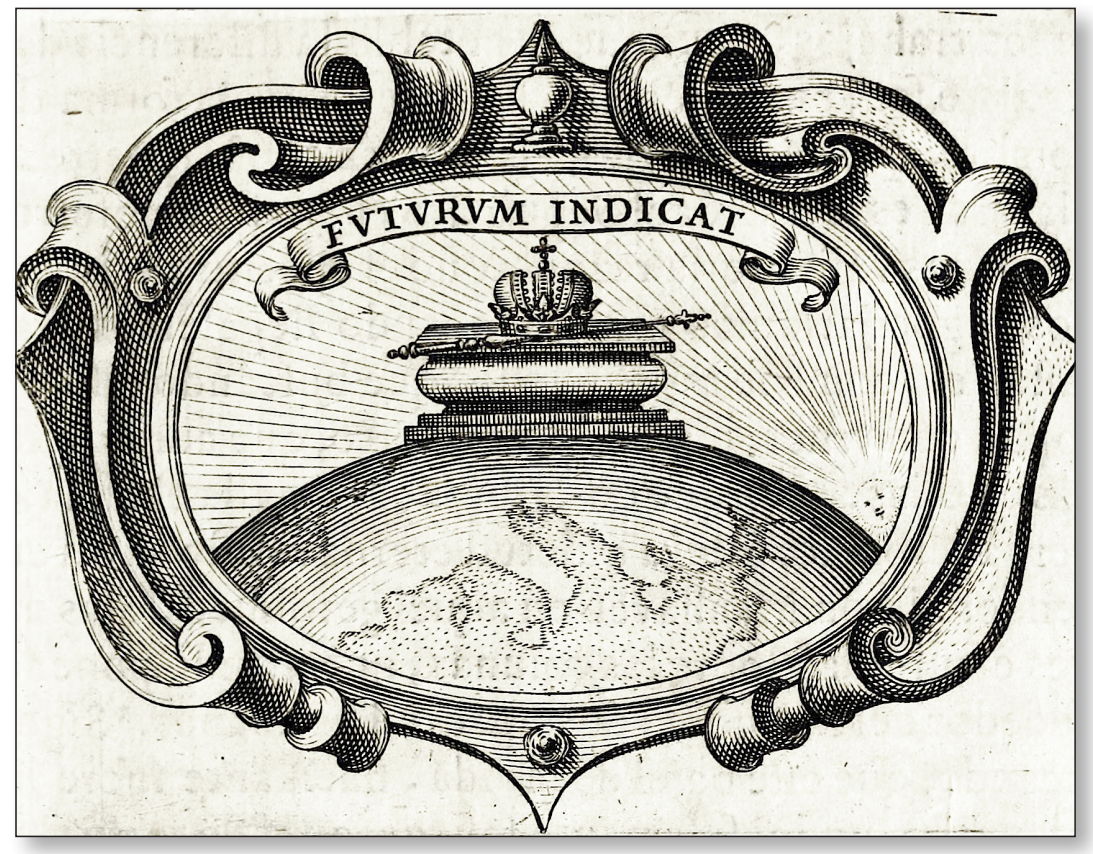

Fig. 10. Diego Saavedra Fajardo, Idea de un príncipe político cristiano. Emp. 101.

Esta última sentencia de Saavedra constituirá el mote del emblema 56 de Hoogstraten con el que concluye nuestro recorrido, "In sepulchro anima verum aeternae quietis thesaurum reperit» [fig.11], que encuentra su fundamento en los capítulos 91 a 93 de fray Diego: «De la brevedad de la vida del hombre", "Por qué quiso Dios que fuese breve nuestra vida», y «De los peligros de la vida del hombre». En este último se localiza la sentencia veterotestamentaria que da lugar a la pictura: «su día florecerá así como la flor en el campo» ${ }^{14}$ (Estella, 1980: 239; Hoogstraten, 1668: 181).

La idea de vanitas, alegorizada por una flor, protagoniza los escritos que inciden en la repentina muerte: "¿Qué es la vida sino un continuo temor de la muerte, sin haber cosa que nos asegure de su duración?», pregunta Saavedra (1999: 1039); responde Hoogstraten (1668: 184): “¿cómo podemos temer cuando Él nos quiere guiar por el puente de la muerte hasta el cielo?»; y da las claves Estella (1980: 239): "pues de tantos peligros anda tu vida cercada, justo es que vivas siempre virtuosamente». El trasfondo de esta enseñanza se encuentra en despreciar todos los deleites de la vida mundana para caminar por el sendero de la virtud, ya que no existe prueba alguna que nos asegure la longevidad de la vida, puesto que la muerte no distingue entre edades ni estamentos.

De esta manera, finaliza juiciosamente Estella (1980: 240): «¿Qué se hicieron tantos reyes y príncipes como hubo en el mundo?»; por su parte, intimida Hoogstraten (1668: 183): «seas quien seas, créenos»; y por último, Saavedra (1999: 1049) cierra su obra: "¿Qué os arrogáis, joh príncipes!, joh reyes!, si en los ultrajes de la muerte fría comunes sois con los demás mortales?». 


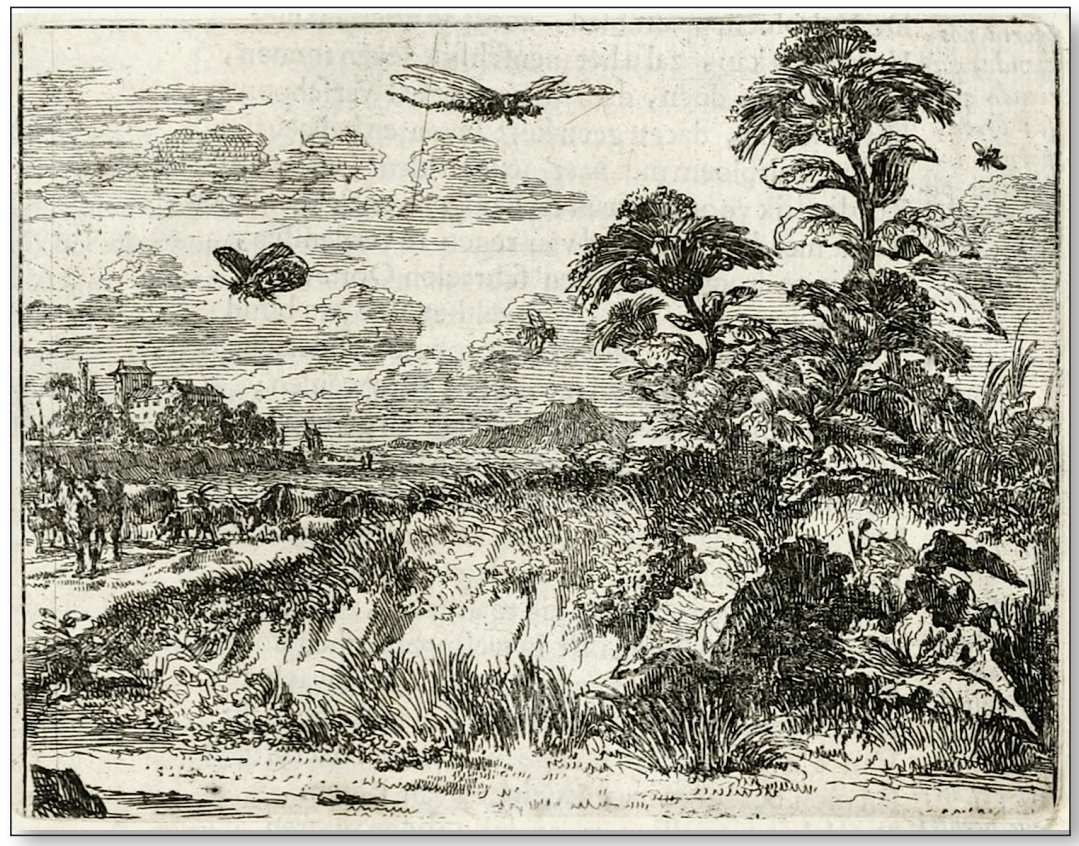

Fig. 11. François van Hoogstraten, Antesala del alma. Embl. 56.

\section{CONCLUSIONES}

Concluye aquí nuestro recorrido que permite comprender que la inserción de Saavedra en Antesala encierra un objetivo claro: complementar y actualizar el mensaje que había expuesto Estella un siglo antes. El repertorio neerlandés trata de reinterpretar los conceptos La Vanidad; para ello, considera al emblemista hispano indispensable, ya que dialoga con su compatriota gracias al ensamblaje que realiza Hoogstraten a través de distintos ejemplos relativos a la moral en primer lugar; a la fama, vanagloria y poder en segundo; y por último, a la muerte.

Estos sirvieron tanto en el siglo XVI como en el XVII a destinatarios de dos países, dos estamentos y dos culturas como una confluencia de valores morales y éticos a través de los cuales se alcanza el camino de la perfección y la obtención de la gloria eterna.

\section{BIBLIOGRAFÍA}

Cazalla Canto, S. [2017a]. «La mística hispana convertida en emblemática neerlandesa: de Fray Diego de Estella a François van Hoogstraten", en $11^{e}$ Congrès International de la Society for Emblem Studies. (En prensa).

Cazalla Canto, S. [2017b]. "Vanidad de fiestas, banquetes y saraos: de fray Diego de Estella a la emblemática neerlandesa», en II Simposio Internacional. Teatro y fiesta en el Siglo de Oro: España y América. (En prensa).

IMAGO, NÚM. 10, 2018, 199-216 
Cazalla Canto, S. [2017c]. "Dos Diegos Hispanos para un libro de emblemas neerlandés», en XI Congreso Internacional de la Sociedad Española de Emblemática. (En prensa).

Díez de Revenga, F.J. [1988]. Diego Saavedra Fajardo. Empresas Políticas, Barcelona, Planeta.

Estella, D. [1980]. Tratado de La Vanidad del mundo (ed. P. Sagüés Azcona), Madrid, Aranzazu.

Hoogstraten, F. [1668]. Het voorhof der ziele, Rotterdam, Imprenta de François van Hoogstraten.

SAAVEDRA FAJARDO, D. [1659]. Idea principis christiano-politici 101 sijmbolis expressa, Ámsterdam, Imprenta de Joannem Jacobi Schipper.

SAAVEDRA FAJARDo, D. [1999]. Empresas políticas (ed. S. López Poza), Madrid, Cátedra.

SÉneCA. [1884]. Epístolas Morales (trad. F. Navarro y Calvo), Madrid, Luis Navarro. 